\title{
Paranaguá: uma política de famílias
}

Fernanda Caroline Gomes Pires ${ }^{1}$

- Enviado em 30/09/2017

- Aprovado em 08/12/2017

\section{INTRODUÇÃO}

O conceito de política mais geral indica que essa é a arte ou ciência de governar, que deve ser voltado aos interesses populares por meio da democracia, onde esses cidadãos elegem seus líderes para representá-los. Mas, é preciso analisar até onde essa democracia se faz presente e a partir de qual momento uma família monopoliza o poder através de gerações para interesses próprios sem que seus eleitores percebam.

Para analisar tal situação tomaremos como base a cidade de Paranaguá e seus representantes municipais, examinando suas histórias, trajetória, família e governo.

\section{HISTÓRIA DE PARANAGUÁ}

Por volta de 1550, através da Ilha da Cotinga ocorreu à primeira povoação onde hoje é a atual cidade de Paranaguá, que já era habitada por diversos índios Carijó. Com a descoberta de ouro no rio dos Almeidas, rio Guaraguaçu e rio dos Correias, logo outros faiscadores começaram a procurar a cidade, e como a relação entre índios e povoadores era amistosa, os índios começaram a ceder para seus colonizadores. (HISTÓRIA, 2017). 
Com o crescimento do povoado, em 1646, o Capitão Provedor Gabriel de Lara mandou erguer o Pelourinho, como símbolo de justiça e poder, após dois anos na data de 29 de Julho de 1648, a Aldeia é elevada a condição de Vila, em 1660 tornando-se Capitania e por fim em 5 de fevereiro de 1842 à condição de cidade. (HISTÓRIA, 2017).

\section{ELEMENTOS BIOGRÁFICOS E TRAJETÓRIA DOS PREFEITOS DE PARANAGUÁ (1952 - 2016)}

\section{Roque Vernalha 1952 - 1956}

Nasceu em 12 de outubro de 1894 na cidade de São Roque, São Paulo. Filho de Domingos Vernalha e Rosália Vernalha. Concluiu o estudo primário e secundário na cidade natal e depois de se mudar para o Paraná formou-se em medicina pela Universidade Federal, no dia 19 de dezembro de 1921. (NOMES, 2012).

Atuou como "médico da Profilaxia Rural do Estado do Paraná (1922), tendo sob a sua responsabilidade todo o litoral paranaense, vereador à câmara Municipal de Paranaguá, de cuja Casa foi seu presidente; prefeito de Paranaguá por duas vezes. A primeira por nomeação e a segunda por eleição (1952)". (NOMES, 2012).

Em 1947 foi eleito vereador de Paranaguá com 344 votos pelo Partido Social Democrático (PSD). Em 1951 candidatou-se a prefeitura concorrendo com Dr $^{\circ}$ Hugo Correa e José das Dores Camargo, venceu a eleição com 2361 votos pelo Partido Social Democrático (PSD). (RESULTADOS, 1947; RESULTADOS, 1951).

Faleceu no dia 28 de janeiro de 1956, em Curitiba, sendo enterrado em Paranaguá conforme seu desejo.

\section{João Eugenio Cominese 1956 - 1960}

Eleito prefeito em 1956, pelo Partido Social Democrático (PSD), com 1.917 votos. (RESULTADOS, 1955).

Não foi encontrada biografia do mesmo. 


\title{
Joaquim Tramujas 1960 - 1964
}

Nasceu em Paranaguá, no dia 19 de maio de 1914. Filho de José Tramujas e Albina Martins Tramujas. Casado com Vera de Souza e Silva, com quem teve dois filhos: Joaquim Tramujas Filho e Olga Maria Tramujas Bassaneze. Realizou seus estudos primários na cidade natal e o secundário em Curitiba, formando-se médico na Universidade Federal do Paraná em 1934. (PRESIDENTE, 2017)

Depois de formado regressou a cidade natal. Dentro da área da saúde atuou como médico na Santa Casa de Misericórdia de Paranaguá. Formado também em magistério lecionou no Colégio Estadual Alberto Gomes Veiga, Colégio Estadual José Bonifácio e Escola Normal Doutor Caetano Munhoz da Rocha Neto.

Foi eleito vereador em 1947 e reeleito em 1951 pelo Partido Social Democrático (PSD), sendo que de 1952 a 1954 foi presidente da Câmara Municipal de Paranaguá, foi eleito prefeito no ano de 1959, com 2.816 votos. (RESULTADOS, 1947; RESULTADOS 1951; RESULTADOS, 1959).

Além da carreira política atuou nos mais diversos campos:

\begin{abstract}
Atendeu o Instituto de Aposentadoria e Pensões dos Bancários, dos Empregados em Transportes e Cargas, da Confraria de São Vicente de Paula, do Instituto Brasileiro do Café e da Associação dos Funcionários Públicos do Estado. Colaborou intensamente em todas as atividades sociais e culturais, cívicas, esportivas e assistenciais da Cidade. Prestou serviços ao Seleto Esporte Clube como Presidente da entidade. Também ao Clube Literário de Paranaguá, onde foi Orador, $1^{\circ}$ Secretário e VicePresidente. (NOMES,2016).
\end{abstract}

Faleceu no dia 07 de abril de 1987.

\section{Brasilio Abud 1964 - *}

Foi eleito como verador no ano de 1951 com 181 votos pelo PSD - PTB. Assumiu seu mandato de prefeito no ano de 1964 , elegendo-se com 4.375 votos pelo Partido Trabalhista Brasileiro (PTB), tendo seu mandato cassado devido à ditadura. (RESULTADOS, 1951; RESULTADOS 1963).

Não foi encontrada biografia do mesmo. 


\section{Constantino João Kotzias 1968 - 1972}

Filho de pais oriundos da Grécia, João Kotzias e Cristina Teodoris, tiveram 9 filhos incluindo Constantino. Após auxiliar na construção do Canal do Paramá se mudaram para Paranaguá onde criaram seus filhos e deram reconhecimento a família atuando na área de distribuição de bebidas. (KOTZIAS, 2009).

Constantino casou-se com Luíza Kotzias com quem teve três filhos, João, Cristina e Leonor. Eleito vereador em 1959 com 233 votos. Assumiu como prefeito de Paranaguá no ano de 1968 com 11.270 votos pelo partido Arena. (RESULTADOS, 1959; RESULTADOS, 1968).

\section{Nelson de Freitas Barbosa 1972 - 1976}

Foi eleito como vereador em 1959 com 120 votos pelo Partido Trabalhista Brasileiro - PTB e prefeito em 1972, com 4.269 votos pelo partido Arena 2. (RESULTADOS, 1959; RESULTADOS, 1972).

Como dito pelo Presidente do Instituto Histórico Geográfico Paranaense: "Com grande dedicação à área cultural. Foi na sua gestão como prefeito que Paranaguá ganhou a Biblioteca Pública e criou-se o Conselho de Cultura." (PRESIDENTES, 2017).

\section{José Vicente Elias 1976 - 1982 / 1988 - 1992}

Nasceu em 1937, em Paranaguá. Filho de Júlio Groth Elias e Anathália Rodrigues Elias. Graduado em Direito pela Faculdade de Direito de Curitiba em 1968.

O início de sua vida política começa ainda na juventude quando presidiu o Centro Estudantil Fernando Amaro, obtendo conquistas como a instalação da Faculdade Estadual de Educação Ciências e Letras de Paranaguá - FAFIPAR. Exerceu o cargo de Diretor Administrativo da APPA - Associação dos Portos de Paranaguá e Antonina, também atuou como superintendente da SUDEPE/SUL - Superintendência do Departamento da Pesca no Sul e CONAP - Companhia Nacional de Abastecimento para o Paraná e Santa Catarina. (LEGADO, 2014). Em 1976, coligado ao PTB é eleito prefeito de Paranaguá exercendo o primeiro mandato até 1982 COM 7.745 votos, sendo reeleito em 1988 com 22.130 votos. (RESULTADOS, 1976; RESULTADOS, 1988). 
Foi assassinado em seu apartamento na cidade de Curitiba em 2003.

\section{Waldir Salmon 1982 - 1988}

Nasceu em 1934. Foi casado com Sueli Gnata com quem teve cinco filhos. Antes da vida política foi diretor da APPA - Administração dos Portos de Paranaguá e Antonina e da Companhia de Água e Esgoto de Paranaguá, atuou também como professor na FAFIPAR - Faculdade Estadual de Educação Ciências e Letras de Paranaguá. (EX-PREFEITO, 2017).

Foi eleito em 1982 pelo Partido do Movimento Democrático Brasileiro (PMDB), exerceu mandato ate $\mathrm{o}$ ano de 1988. (RESULTADOS, 1982).

O prefeito ficou marcado por realizar uma gestão com grandes obras, como a construção do Terminal Rodoviário Municipal, Ginásio de Esportes Albertina Salmon, Escola de Educação Especial Eva Cavani e o Programa de Estacionamento Regulamentado - PERTO.

Faleceu no dia 16 de outubro de 2016, aos 83 anos em Curitiba e foi enterrado em Paranaguá conforme desejo.

\section{Carlos Antonio Tortato 1992 - 1996}

Nasceu em 21 de agosto de 1956, em Curitiba. Carlos Antonio Tortato iniciou sua carreira como presidente do Sindicato dos Conferentes do Porto de Paranaguá, se elegeu como prefeito em 1992 com 17.630 votos pelo PMDB, exercendo mandato até o ano de 1996. (RESULTADOS, 1992

\section{Mário Manoel das Dores Roque 1996 - 2004 / 2013 - *}

Nasceu no dia 29 de maio de 1942 na Angola, chegou ao Brasil no fim da década de 50. Filho de Antônio Jacinto Roque e Etelvina das Dores. Trabalhou como vigia portuário, logo ocupou a presidência do Sindicato dos Vigias de Paranaguá. 
Em 1992, candidatou-se a vereador pelo PST (Partido Social Trabalhista), se elegeu com 886 votos. Logo após eleito ocupou a presidência da câmara, cargo que mais tarde viria a ser ocupado pelo filho, Marquinhos Roque. (FAMILIA, 2013).

No ano de 1996 concorreu a prefeitura de Paranaguá vencendo com 26.101 votos pelo PSDB, se reelegendo no ano de 2000. Em 2010 assumiu o lugar de Fernando Ribas Carli Filho como deputado estadual da ALEP-Pr (Assembleia Legislativa do Paraná) após o mesmo renunciar o cargo, Roque ocupou a vaga até o ano de 2011, tendo a vaga questionada pelo TER-Pr. Em 2012 se reelegeu prefeito na cidade de Paranaguá. (RESULTADOS, 1996; RESULTADOS,2012).

Faleceu no dia 01 de julho de 2013, aos 72 anos.

\title{
José Baka Filho 2004 - 2012
}

Nasceu em 27 de novembro de 1962, em Paranaguá. Filho de Ruth Crocetti Baka e José Baka. Casado com Jozaine Baka, com quem teve duas filhas. Formado em Engenharia Cívil pela Universidade Federal do Paraná. Iniciou sua carreira trabalhando como engenheiro na Administração dos Portos de Paranaguá e Antonina. (BAKA, 2014).

Em um mandato de 8 anos, o prefeito é lembrado pelos casos de corrupção, em um esquema que desviava dinheiro da alimentação escolar do município.

\begin{abstract}
De acordo com o MP-PR, a SP Alimentação doou R \$ 40 mil para a campanha de Baka com o compromisso de ser contratada em caso de vitória do pedetista. O dinheiro teria sido entregue em duas parcelas de $\mathrm{R} \$ 20$ mil, nos meses de agosto e setembro de 2004. Além do dinheiro, Baka teria recebido ainda outras vantagens ofertada pelo grupo: pagamento de advogados, despesas de viagens e até mesmo ingressos para o musical O Fantasma da Ópera, exibido na capital paulista, teriam sido bancados pelo cartel, conforme a ação proposta pela promotoria." (MP, 2012).”
\end{abstract}

No segundo mandato do Prefeito José Vicente Elias, entre os anos de 1992 e 1996, atuou como Secretário do Meio Ambiente e Serviços Urbanos. Já nos dois primeiros mandatos do Prefeito Mário Roque, entre 1996 e 2004, foi vice-prefeito e Secretário de Obras. (VIDA,2008)

Baka foi eleito em 2004 pelo PDT com 37.005 votos. (BAKA,2014). 


\section{Edson de Oliveira Kersten 2013 - 2016}

Nasceu em Itaporanga, São Paulo, no dia 07 de julho de 1952. Cursou ensino superior completo formando-se em medicina. Casado com Terezinha Flenik Kersten, que atuou como Secretária Municipal da Saúde, o casal possui uma filha, Amanda Flenik Kersten, também médica concursada pela prefeitura. (EDSON, 2013).

Em 1992, candidatou-se a vereador pelo PPS (Partido Popular Socialista), com 412 votos não conseguiu se eleger. Novamente tentando concorrer ao cargo, aliou-se ao PDT (Partido Democrático Trabalhista), se elegendo com 1.162 votos no ano de 1996 e suplente nas eleições de 2000 e 2004. (RESULTADOS,1992; RESULTADOS,1996; RESULTADOS,2000; RESULTADOS,2004).

Foi eleito em 2012 como vice-prefeito pelo PMDB (Partido do Movimento Democrático Brasileiro). Em 2013 assumiu a prefeitura da cidade após o falecimento de Mário Roque atuando até o fim de 2016.

\section{Marcelo Elias Roque 2016 - *}

Nasceu em Paranaguá, no dia 29 de novembro de 1973. Filho do ex Prefeito Mário Manoel das Dores Roque e Maria de Lourdes Elias Nunes. Casado com Amanda Pereira Roque, com quem tem três filhos. Concluiu seus estudos primário e secundário na cidade natal, e posteriormente atuou como Servidor Público Municipal. (VIDA,2016).

Aos 23 anos assumiu a diretoria da Fábrica de Artefatos da cidade. Na primeira gestão de seu pai, Mário Roque (1996 - 2004), auxiliou em projetos como “Minha Rua" que oferecia calçadas para os cidadãos, também auxiliou na obra da Praça 29 de Julho, inaugurada em 1999 em honra a data de aniversário da cidade, além de participar da obra de abertura da Avenida Bento Munhoz da Rocha Neto, uma das mais importantes da cidade. (CONHEÇA, 2015).

Já no segundo mandato de seu pai, ano de 2013, atuou como Secretário do Meio Ambiente. Consolidou-se ao PV (Partido Verde), em 2014, concorrendo a deputado federal, com quase 20 mil votos não conseguindo se eleger. No ano de 2016 lançou sua candidatura a prefeito do munícipio de Paranaguá, elegendo-se com 44\% de aprovação (32.299 votos) tendo como vice Arnaldo de Sá Maranhão Junior, do partido PSB (Partido Socialista Brasileiro). (VIDA,2016). 


\section{ANÁLISE PROSOPOGRÁFICA}

\section{Biografias}

A tabela a seguir ilustra de forma sucinta os aspectos biográficos dos prefeitos da cidade de Paranaguá afim de melhor compreender as características em comum que traçam o perfil desses políticos.

TABELA 1 - ASPECTOS BIOGRÁFICOS

\begin{tabular}{|c|c|c|c|c|c|}
\hline Prefeito & $\begin{array}{l}\text { Período de } \\
\text { Mandato }\end{array}$ & $\begin{array}{c}\text { Data e Local de } \\
\text { Nascimento }\end{array}$ & $\begin{array}{l}\text { Formação } \\
\text { Acadêmica }\end{array}$ & $\begin{array}{l}\text { Atividade } \\
\text { Profissional }\end{array}$ & Partido Político \\
\hline Roque Vernalha & 1952 - 1956 & São Paulo & Medicina & Médico & PSD \\
\hline $\begin{array}{l}\text { João Eugenio } \\
\text { Cominese }\end{array}$ & $1956-1960$ & - & -- & - & PTB, PSB, PDC \\
\hline Joaquim Tramujas & $1960-1964$ & Paranaguá & $\begin{array}{l}\text { Medicina e } \\
\text { Magistério }\end{array}$ & Médico & PDC, PTN, PSB \\
\hline Brasilio Abud & $1964-*$ & - & - & Comerciante & PTB \\
\hline $\begin{array}{c}\text { Constantino João } \\
\text { Kotzias }\end{array}$ & $1968-1972$ & - & - & Comerciante & ARENA \\
\hline $\begin{array}{c}\text { Nelson de Freitas } \\
\text { Barbosa }\end{array}$ & 1972 - 1976 & - & - & - & ARENA II \\
\hline José Vicente Elias & $\begin{array}{c}1976-1982 \text { e } \\
1988-1992\end{array}$ & Paranaguá & Direito & Diretor da APPA & ARENA, PTB \\
\hline Waldir Salmon & $1982-1988$ & - & Magistério & Diretor da APPA & PMDB \\
\hline Carlos Antonio Tortato & $1992-1996$ & Curitiba & $\begin{array}{l}\text { Superior não } \\
\text { informado }\end{array}$ & $\begin{array}{c}\text { Presidente de } \\
\text { Sindicatos da APPA }\end{array}$ & PMDB \\
\hline $\begin{array}{l}\text { Mario Manoel das } \\
\text { Dores Roque }\end{array}$ & $\begin{array}{c}1996-2004 \mathrm{e} \\
2013\end{array}$ & Angola & - & $\begin{array}{c}\text { Presidente de } \\
\text { Sindicatos da APPA }\end{array}$ & PST, PSDB \\
\hline José Baka Filho & $2004-2012$ & Paranaguá & $\begin{array}{c}\text { Engenheiro } \\
\text { Cívil }\end{array}$ & $\begin{array}{c}\text { Engenheiro da } \\
\text { APPA }\end{array}$ & PDT \\
\hline $\begin{array}{l}\text { Edson de Oliveira } \\
\text { Kersten }\end{array}$ & $2013-2016$ & São Paulo & Medicina & Médico & PMDB \\
\hline Marcelo Elias Roque & 2016 - - & Paranaguá & - & Servidor Público & PV \\
\hline
\end{tabular}

Fonte: Tabela organizada pela autora. 
Da mesma forma que os aspectos biográficos compõem sua trajetória é importante analisar as composições familiares e o quão envolvido estão por meio de laços sanguíneos.

TABELA 2 - PARENTESCO NA POLÍTICA

\begin{tabular}{|c|c|c|c|}
\hline Nome & Parente & Grau de Ligação & Cargo Ocupado \\
\hline \multirow{4}{*}{ Marcelo Elias Roque } & Mario Manoel das Dores Roque & Pai & Prefeito \\
\hline & Marcus Antonio Elias Roque & Irmão & $\begin{array}{c}\text { Presidente da Câmara de } \\
\text { Vereadores }\end{array}$ \\
\hline & Brayan Roque & Filho & Secretário de Trabalho \\
\hline & Camila Roque & Sobrinha & $\begin{array}{l}\text { Secretária de } \\
\text { Comunicação }\end{array}$ \\
\hline \multirow{2}{*}{$\begin{array}{l}\text { Edson de Oliveira } \\
\text { Kersten }\end{array}$} & Terezinha Kersten & Esposa & Secretária da Saúde \\
\hline & Amanda Flenik Kersten & Filha & Médica da Prefeitura \\
\hline José Baka Filho & Jozaine Baka & Esposa & $\begin{array}{l}\text { Secretária de } \\
\text { Planejamento }\end{array}$ \\
\hline \multirow{2}{*}{$\begin{array}{l}\text { Mario Manoel das } \\
\text { Dores Roque }\end{array}$} & Marcelo Elias Roque & Filho & Supersecretária \\
\hline & Marcus Antonio Elias Roque & Filho & $\begin{array}{c}\text { Presidente da Câmara de } \\
\text { Vereadores }\end{array}$ \\
\hline \multirow{2}{*}{ José Vicente Elias } & Juliano Vicente Elias & Filho & Secretário de Obras \\
\hline & Fabiano Vicente Elias & Filho & Secretário de Segurança \\
\hline Brasilio Abud & Nilo Abud & Irmão & Cargo não encontrado \\
\hline
\end{tabular}

Fonte: Tabela organizada pela autora.

Na Tabela 2 é possível compreender que desde os primeiros prefeitos a relação entre família e política se perpetua por mandatos e quase como uma regra assim que eleito se faz um dever nomear algum parente para determinado cargo.

Conforme indicado na tabela, dos 13 prefeitos analisados 6 indicaram algum familiar para cargos ou já possuíam parentes dentro da política. "Existe uma significativa transferência de capital político por meio das relações de parentesco [...] que é transferido por meio de maridos e pais" (GOULART, 2016, p.318).

Somente o atual prefeito Marcelo Roque, eleito em 2016, desde sua posse indicou três parentes para ocupar cargos dentro da prefeitura, o filho Brayan Roque ocupa a Secretária de 
Trabalho, é formado em Administração pelo Instituto Superior do Litoral do Paraná - ISULPAR, a sobrinha Camila Roque ocupa a Secretária de Comunicação, é formada em jornalismo e o irmão Marcus Roque ocupa a presidência da câmara, já se elegeu como vereador nos anos de 2012 e 2016. Antes de se tornar prefeito, Marcelo já ocupava o cargo de servidor público da prefeitura durante a gestão de seu pai, ex-prefeito Mario Roque que no seu segundo mandato indicou o filho a Secretário do Meio Ambiente. Mas, Marcelo não é único a indicar parentes próximos, além de esposas e irmãos, é possível perceber que dos seis prefeitos, quatro nomearam os próprios filhos, uma forma clara de manter a tradição política da família, colocando desde cedo seus herdeiros a seguir os passos dos pais. "Família ainda importa. As estruturas de parentesco formam parte da realidade social e política brasileira no século XXI." (OLIVEIRA,2012, p.13).

\section{Escolaridade e Área Profissional}

Na Tabela 3 e 4 é possível perceber que todos os prefeitos eleitos possuem escolaridade básica concluída destacando-se em maior número os que possuem ensino superior completo e trabalham em áreas de maior contato com o povo, além de quase metade ter passado por cargos importantes dentro do Porto ganhando reconhecimento do povo e apoio de grandes empresários.

TABELA 3 - ESCOLARIDADE

\begin{tabular}{|c|c|c|}
\hline Grau de Instrução & Total de prefeitos & Nome \\
\hline Médio Incompleto & 0 & - \\
\hline \multirow{3}{*}{ Médio Completo } & \multirow{3}{*}{3} & Constantino João Kotzias \\
\hline & & Mario Manoel das Dores Roque \\
\hline & & Marcelo Elias Roque \\
\hline \multirow{7}{*}{ Superior Completo } & \multirow{7}{*}{7} & Roque Vernalha \\
\hline & & Joaquim Tramujas \\
\hline & & José Vicente Elias \\
\hline & & Waldir Salmon \\
\hline & & Carlos Antonio Tortato \\
\hline & & José Baka Filho \\
\hline & & Edson de Oliveira Kersten \\
\hline
\end{tabular}




\begin{tabular}{|c|c|c|}
\hline \multirow{2}{*}{ Não Informado } & \multirow{2}{*}{3} & João Eugenio Cominese \\
& & Brasílio Abud \\
& & Nelson de Freitas Barbosa \\
\hline
\end{tabular}

Fonte: Tabela organizada pela autora.

TABELA 4 - FORMAÇÃO ACADÊMICA SUPERIOR

\begin{tabular}{|c|c|c|c|}
\hline Formação & Total & Porcentagem & Nome \\
\hline Direito & 1 & $14,3 \%$ & José Vicente Elias \\
\hline \multirow{3}{*}{ Medicina } & \multirow{3}{*}{3} & \multirow{3}{*}{$42,8 \%$} & Roque Vernalha \\
\hline & & & Joaquim Tramujas \\
\hline & & & Edson de Oliveira Kersten \\
\hline \multirow{2}{*}{ Magistério } & \multirow{2}{*}{2} & \multirow{2}{*}{$28,6 \%$} & Joaquim Tramujas \\
\hline & & & Waldir Salmon \\
\hline Engenharia & 1 & $14,3 \%$ & José Baka Filho \\
\hline
\end{tabular}

Fonte: Tabela organizada pela autora.

Tendo em vista que dos dez prefeitos que se tem conhecimento da formação acadêmica sete possuem ensino superior completo, destacando-se a medicina como quase metade das graduações, vindo em segundo lugar o magistério, sendo que o ex-prefeito Joaquim Tramujas (mandato de 1960-1964) concluiu as duas formações. Todos os sete prefeitos com ensino superior chegaram a atuar em algum momento dentro da sua formação, mesmo que depois desviassem sua carreira profissional de alguma forma, eles ganharam reconhecimento e admiração atuando em serviço do povo como médicos e professores, sendo responsáveis por grandes mudanças antes e depois de sua gestão.

TABELA 5 - ÁREA DE ATUAÇÃO PROFISSIONAL

\begin{tabular}{|c|c|c|c|}
\hline Atuação & Total & Porcentagem & Nome \\
\hline \multirow{2}{*}{ Comércio } & \multirow{2}{*}{2} & \multirow{2}{*}{$18,18 \%$} & Brasílio Abud \\
\hline & & & Constantino João Kotzias \\
\hline \multirow{3}{*}{ Medicina } & \multirow{3}{*}{3} & \multirow{3}{*}{$27,27 \%$} & Roque Vernalha \\
\hline & & & Joaquim Tramujas \\
\hline & & & Edson de Oliveira Kersten \\
\hline Serviço Público & 1 & $9,09 \%$ & Marcelo Elias Roque \\
\hline
\end{tabular}




\begin{tabular}{|c|c|c|c|}
\hline \multirow{2}{*}{ Cargos na APPA } & \multirow{2}{*}{5} & \multirow{3}{*}{$45,45 \%$} & Wosé Vicente Elias \\
\cline { 3 - 3 } & & & Carlos Antonio Tortato \\
\cline { 3 - 3 } & & & Mario Manoel das Dores Roque \\
\cline { 3 - 3 } & & & José Baka Filho \\
\hline
\end{tabular}

Fonte: Tabela organizada pela autora.

Até a década de 80 , esses prefeitos ganharam a confiança do povo ao se elegerem por atuarem a serviço da comunidade como profissionais da saúde e comércio, mas após esse período é possível analisar conforme a Tabela 5 que começam a ganhar destaque dentro da política funcionários da APPA, sendo que dos 5 prefeitos 2 atuaram como diretores, 2 na presidência de sindicatos e 1 como engenheiro. Isso mostra a influência que o porto exerce sobre a política.

Como já citado anteriormente, quando a família não exerce política direta ela pode exercer de forma indireta, é o caso da família do ex-prefeito João Eugenio Cominese, que apesar de não seguirem os passos do pai, possuem imenso controle sobre a cidade comandando o grupo de empresas Rocha Terminais Portuários e Logística, fundado em 1864 por Bento Munhoz da Rocha, onde mais tarde a família Cominese viria a se tornar sócia, fazendo parte de uma história com mais de 150 anos que passa sua gestão por gerações controlando grande parte do capital portuário da cidade.

\section{CONSIDERAÇÕES FINAIS}

Após análise de diversos aspectos pessoais e profissionais é possível perceber que a política se faz em família, com o apoio dos que possuem laços familiares e buscam os mesmos interesses. "Diante deste quadro, o nepotismo e seus tentáculos é, sobretudo, "um processo de produção e reprodução de desigualdades", muitas vezes organizado por redes familiares em um dado espaço e tempo." (VALENCIANO,2013, p.101).

"O sobrenome conhecido, respeitado e admirado, pode ser considerado, nas eleições municipais, um valioso instrumento de marketing político. Ele possui potencial eleitoral que, explorado de maneira adequada, pode levar o candidato à vitória." (BERNARDI, 2015, p.22). Com 
influencia do sobrenome, mesmo aqueles que não ingressam na área política se favorecem dentro de grandes empresas e comandando importantes setores, controlando a política de forma indireta.

Dentro de uma cidade portuária como Paranaguá não é espantoso obter como número que quase metade dos prefeitos eleitos passaram por cargos dentro a APPA - Associação dos Portos de Paranaguá e Antonina, pois mesmo sendo herdeiros de políticos passados através dessas posições conseguiram ser reconhecido pela parcela mais pobre e o apoio da classe dominante no Porto, assim perpetuam suas histórias e o nome de suas famílias por geração em geração.

\section{REFERÊNCIAS}

BAKA 1234. 2014. Disponível em: <https://www.eleicoes2014.com.br/baka/>. Acesso: 18/09/2017.

CONHEÇA o Marcelo. 2015. Disponível em: <http://marceloroque.com.br/conheca-o-marcelo/>. Acesso em: 16/09/2017.

EDSON Kersten assume prefeitura de Paranaguá. 24 de Junho de 2013. Disponível em: <http://www.paranagua.pr.gov.br/noticias.php?noticia id=4339>. Acesso em: 02/10/2017.

EX-PREFEITO de Paranaguá Waldir Salmon morre aos 83 anos de idade. 16 de Julho de 2017. Disponível em: <https://folhadolitoral.com.br/politica/ex-prefeito-de-paranagua-waldir-salmonmorre-aos-83-anos-de-idade/\#.Wdk3j2hSzIU > Acesso: 25/09/2017.

FAMILIA Roque comanda cidade de Paranaguá. 13 de Janeiro de 2013. Disponível em: $<$ http://www.gazetadopovo.com.br/vida-publica/familia-roque-comanda-cidade-de-paranagua3kes7w2eswnz8de89srwwavf0> Acesso em: 18/09/2017.

GOULART, Mônica H. H. S. As Mulheres na ALEP: Uma abordagem prosopográfica. Nepotismo, Parentesco e Mulheres. Curitiba: 2016.

HISTORIA. 2017. Disponível em: <http://www.paranagua.pr.gov.br/conteudo/a-cidade/historia>. Acesso em: 14/10/2017.

KOTZIAS. 12 de Julho de 2009. Disponível em: <http://costakotzias.blogspot.com.br/2009/07/oskotzias.html>. Acesso em: 19/10/2017.

LEGADO de José Vicente Elias. Disponível em: <http://www.fabianoelias.com.br/site/?page id=18> Acesso em: 24/09/2017. 
MP denuncia prefeito de Paranaguá por receber propina de R\$1,3 milhão. 04 de Junho de 2012. Disponível em: <http://www.gazetadopovo.com.br/vida-publica/mp-denuncia-prefeito-deparanagua-por-receber-propina-de-r-13-milhao-231y0h547dc007r1ilpy1gh1q>. Acesso em: 21/09/2017.

MONTEIRO, Lorena Madruga. Prosopografia de grupos sociais, políticos situados historicamente: método ou técnica de pesquisa?. Pelotas. 2014.

NOMES de Rua: Quem foi Dr Roque Vernalha? 20 de Junho de 2012. Disponível em: < http://culturadematinhos.blogspot.com.br/2012/06/nomes-de-rua-quem-foi-dr-roquevernalha.html> Acesso: 27/09/2017.

NOMES de Rua: Quem foi Joaquim Tramujas? 17 de Fevereiro de 2016. Disponível em: < http://culturadematinhos.blogspot.com.br/2016/02/nome-de-rua-quem-foi-dr-joaquimtramujas.html> Acesso: 27/09/2017.

OLIVEIRA, Ricardo Costa. Na teia do nepotismo. Curitiba. Insight, 2012.

OLIVEIRA, Ricardo Costa. Nepotismo, Parentesco e Mulheres. Curitiba: 2016.

PRESIDENTES do IHGP. 11 de Março de 2017. Disponível em: < https://folhadolitoral.com.br/instituto-historico-e-geografico-de-paranagua/os-presidentes-doihgp/\#.WhnxJOgnHIU> Acesso em: 19/10/2017.

RESULTADOS, eleição de 1947. 16 de Outubro de 1947. Disponível em: < http://apps.trepr.jus.br/files/resultados/19471116A77453.pdf >. Acesso em: 16/10/2017.

RESULTADOS, eleição de 1951. 22 de Julho de 1951. Disponível em : < http://apps.trepr.jus.br/files/resultados/19510722A77453.pdf>. Acesso em: 16/10/2017.

RESULTADOS, eleição de 1955. 03 de Outubro de 1955. Disponível em : < http://apps.trepr.jus.br/files/resultados/19551003A77453.pdf>. Acesso em: 17/10/2017.

RESULTADOS, eleição de 1959. 04 de Outubro de 1959. Disponível em: < http://apps.trepr.jus.br/files/resultados/19591004A77453.pdf> Acesso em: 17/10/2017.

RESULTADOS, eleição de 1963. 06 de Outubro de 1963. Disponível em: < http://apps.trepr.jus.br/files/resultados/19631006A77453.pdff> Acesso em: 19/10/2017.

RESULTADOS, eleição de 1968. 15 de Novembro de 1968. Disponível em: < http://apps.trepr.jus.br/files/resultados/19681115A77453.pdf> Acesso em: 19/10/2017.

RESULTADOS, eleição de 1972. 15 de Novembro de 1972. Disponível em: < http://apps.trepr.jus.br/files/resultados/19721115A77453.pdf> Acesso em: 21/10/2017. 
RESULTADOS, eleição de 1976. 15 de Novembro de 1976. Disponível em: < http://apps.trepr.jus.br/files/resultados/19761115A77453.pdf> Acesso em: 21/10/2017.

RESULTADOS, eleição de 1982. 15 de Novembro de 1982. Disponível em: <http://apps.trepr.jus.br/files/resultados/19821115A77453.pdf> Acesso em: 21/10/2017.

RESULTADOS, eleição de 1988. 15 de Novembro de 1988. Disponível em: <http://apps.trepr.jus.br/files/resultados/19881115A77453.pdf> Acesso em: 21/10/2017.

RESULTADOS, eleição de 1992. 06 de Outubro de 1992. Disponível em: < http://apps.trepr.jus.br/files/resultados/19921003A77453.pdf> Acesso em: 21/10/2017.

RESULTADOS, eleição de 1996. 03 de Outubro de 1996. Disponível em: < http://apps.trepr.jus.br/files/resultados/19961003A77453.pdf> Acesso em: 24/10/2017.

RESULTADOS, eleição de 2000. 01 de Outubro de 2000. Disponível em: <http://apps.trepr.jus.br/files/resultados/20001001A77453.pdf> Acesso em: 24/10/2017.

RESULTADOS, eleição de 2004. 03 de Outubro de 2004. Disponível em: < http://apps.trepr.jus.br/files/resultados/20041003A77453.pdf> Acesso em: 24/10/2017.

RESULTADOS, eleição de 2008. 05 de Outubro de 2008. Disponível em: < http://apps.trepr.jus.br/files/resultados/20081005A77453.pdf> Acesso em: 24/10/2017.

RESULTADOS, eleição de 2012. 07 de Outubro de 2012. Disponível em: < http://apps.trepr.jus.br/files/resultados/20121007A77453.pdf> Acesso em: 25/10/2017.

PRESIDENTE perpétuo. 09 de Abril de 2017. Disponível em: <https://folhadolitoral.com.br/instituto-historico-e-geografico-de-paranagua/o-presidenteperpetuo/\#.WdmBpmhSzIU> Acesso: 25/09/2017.

VALENCIANO, Tiago. As conexões do nepotismo contemporâneo. 2013. Curitiba.

VIDA Pública: gazeta do povo. 03 de Outubro de 2016. Disponível em: <http://www.gazetadopovo.com.br/vida-publica/eleicoes/2016/guia-Candidatos/paranagua$\mathrm{pr} /$ prefeito/marcelo-roque-43/>. Acesso em: 16/09/2017.

VIDA Pública: José Baka Filho. 11 de Agosto de 2008. Disponível em: <http://www.gazetadopovo.com.br/vida-publica/eleicoes/2008/paranaguab4flwbx4jyvulivlru3cjexce> Acesso em: 21/09/2017. 